\title{
sensors
}

ISSN 1424-8220

(C) 2006 by MDPI

http://www.mdpi.org/sensors

\section{Gas Sensing Properties of Ordered Mesoporous $\mathrm{SnO}_{2}$}

Thorsten Wagner $^{1,2, *}$, Claus-Dieter Kohl ${ }^{1}$, Michael Fröba ${ }^{2}$ and Michael Tiemann ${ }^{2}$

${ }^{1}$ Institute of Applied Physics, Heinrich-Buff-Ring 16, D-35392 Giessen, Justus Liebig University, Giessen, Germany

${ }^{2}$ Institute of Inorganic and Analytical Chemistry, Heinrich-Buff-Ring 58, D-35392 Giessen, Justus Liebig University, Giessen, Germany

* Author to whom correspondence should be addressed.

Email: thorsten.wagner@ap.physik.uni-giessen.de

Received: 30 July 2005 / Accepted: 4 January 2006 / Published: 7 April 2006

\begin{abstract}
We report on the synthesis and $\mathrm{CO}$ gas-sensing properties of mesoporous tin(IV) oxides $\left(\mathrm{SnO}_{2}\right)$. For the synthesis cetyltrimethylammonium bromide (CTABr) was used as a structure-directing agent; the resulting $\mathrm{SnO}_{2}$ powders were applied as films to commercially available sensor substrates by drop coating. Nitrogen physisorption shows specific surface areas up to $160 \mathrm{~m}^{2} \cdot \mathrm{g}^{-1}$ and mean pore diameters of about $4 \mathrm{~nm}$, as verified by TEM. The film conductance was measured in dependence on the CO concentration in humid synthetic air at a constant temperature of $300^{\circ} \mathrm{C}$. The sensors show a high sensitivity at low CO concentrations and turn out to be largely insensitive towards changes in the relative humidity. We compare the materials with commercially available $\mathrm{SnO}_{2}$-based sensors.
\end{abstract}

Keywords: Tin oxide, sensing properties, CO, humidity. 


\section{Introduction}

Semiconducting tin dioxide is known to exhibit good gas-sensing properties towards various gases [1]. One of the common ways to tune the sensitivity and selectivity of the materials is to dope them with various noble metals [2]. A simple, yet promising alternative to enhance the gas-sensing performance is to control the morphological features of the materials during the chemical synthesis. In particular, the generation of high specific surface areas and uniform systems of large (meso)pores will result in a higher probability for a gas to interact with the semiconductor, which is likely to increase the sensitivity of the material.

The concept of utilising self-assembled arrays of amphiphiles to synthesise well-ordered mesoporous materials [3] has recently been applied to tin(IV) oxides $\left(\mathrm{SnO}_{2}\right)$ [4-8]. However, only a few of the materials were examined with respect to their gas-sensing properties [6a,8]. Here, we present the synthesis of ordered mesoporous $\mathrm{SnO}_{2}$ by utilisation of $\operatorname{tin}(\mathrm{IV})$ chloride $\left(\mathrm{SnCl}_{4}\right)$ as a precursor and cetyltrimethylammonium bromide $(\mathrm{CTABr})$ as a structure-directing agent, as well as the gas sensing properties of the products.

\section{Experimental}

In a typical synthesis, a solution of $5.1 \mathrm{~g} \mathrm{SnCl}_{4} \cdot 5 \mathrm{H}_{2} \mathrm{O}(98 \%$, Aldrich) in $50 \mathrm{ml}$ water was added to a solution of 6.0 g cetyltrimethylammonium bromide (CTABr, p.a., Merck) in $50 \mathrm{ml}$ water and $4 \mathrm{ml}$ ammonia (25\%). The resulting mixture was adjusted to $\mathrm{pH} 1$ by dropwise addition of $\mathrm{HCl}$, stirred for 3 hours, and heated to $100{ }^{\circ} \mathrm{C}$ in a Teflon-lined autoclave for five days. The solid product was filtered off, dried and calcined at $300{ }^{\circ} \mathrm{C}$ or $450{ }^{\circ} \mathrm{C}$ (see below) in order to remove the structure director (CTABr).

X-ray powder diffraction was carried out with a Bruker AXS D8 Advance diffractometer (filtered $\mathrm{Cu} \mathrm{K} \alpha$ radiation, $40 \mathrm{kV}, 40 \mathrm{~mA}, 2$ seconds counting time per $0.01^{\circ} / 2 \theta$ ). Nitrogen physisorption was performed on a Quantachrome Autosorb 6; samples were degassed for 24 hours at $120^{\circ} \mathrm{C}$ in vacuum. Transmission electron microscopy (TEM) was carried out with a Philips CM30-ST.

For the preparation of the sensors $140 \mathrm{mg}$ of the mesoporous $\mathrm{SnO}_{2}$ powders were ground and dispersed in $1 \mathrm{ml}$ water. The dispersion was deposited onto substrates (Umweltsensortechnik, UST) with integrated heating and interdigitally structured platinum electrodes, dried at room temperature, and tempered for 60 hours at $350^{\circ} \mathrm{C}$. The gas-sensing properties were measured by means of a gasmixing equipment using standard mass-flow controllers to provide a well-defined gas flow and a computer to control the experiment and record the resulting data.

\section{Results and discussion}

Figure 1 shows the X-ray diffraction (XRD) pattern of a representative sample after calcination at $300{ }^{\circ} \mathrm{C}$. The broad reflection in the low angle region $\left(2 \theta=1^{\circ}\right)$ is indicative of a disordered mesopore structure; this is supported by TEM (Figure 2a). The nitrogen physisorption isotherm and the pores size distribution (calculated by the BJH method) of the respective sample is shown in Figure 3; the specific surface area (BET method) is $160 \mathrm{~m}^{2} \cdot \mathrm{g}^{-1}$. 
A calcination temperature of $300{ }^{\circ} \mathrm{C}$ is generally not sufficient for a quantitative removal of $\mathrm{CTABr}$ from the pores; accordingly, the samples show a greyish (instead of white) colour after calcination. A higher calcination temperature results in considerable a loss of the mesoscopic structure as evidenced by the disappearance of the XRD reflection and a substantial decrease in the specific surface area $\left(75 \mathrm{~m}^{2} \cdot \mathrm{g}^{-1}\right)$. However, it was found that all remaining organic residues in the samples calcined at $300{ }^{\circ} \mathrm{C}$ are removed upon long-term tempering of the sensors at $350{ }^{\circ} \mathrm{C}$ without any loss in mesostructure. This is confirmed by TEM (Figure 2b) as well as by the absence of bromine as evidenced by EDX.

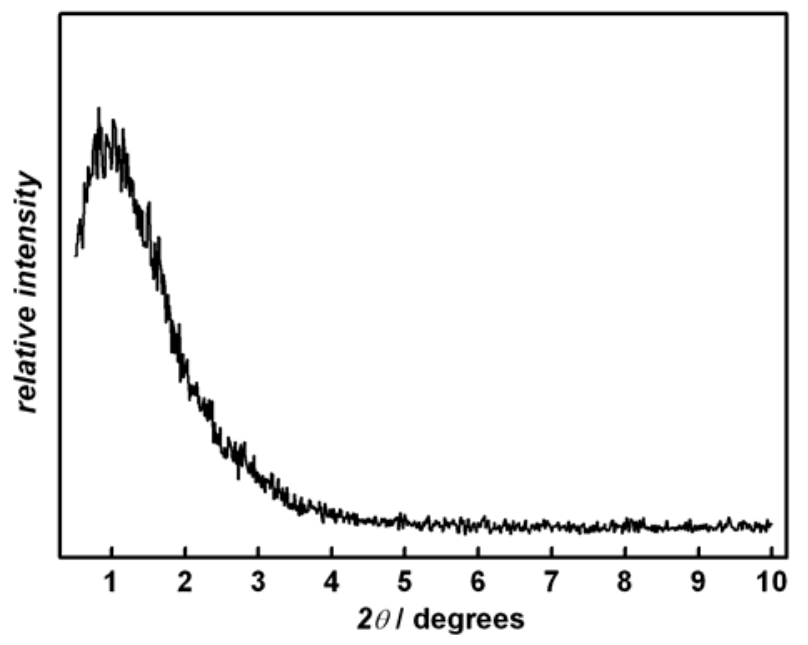

Figure 1. Powder X-ray diffraction diagram of mesoporous $\mathrm{SnO}_{2}$. The broad low-angle reflection indicates a disordered mesopore structure.

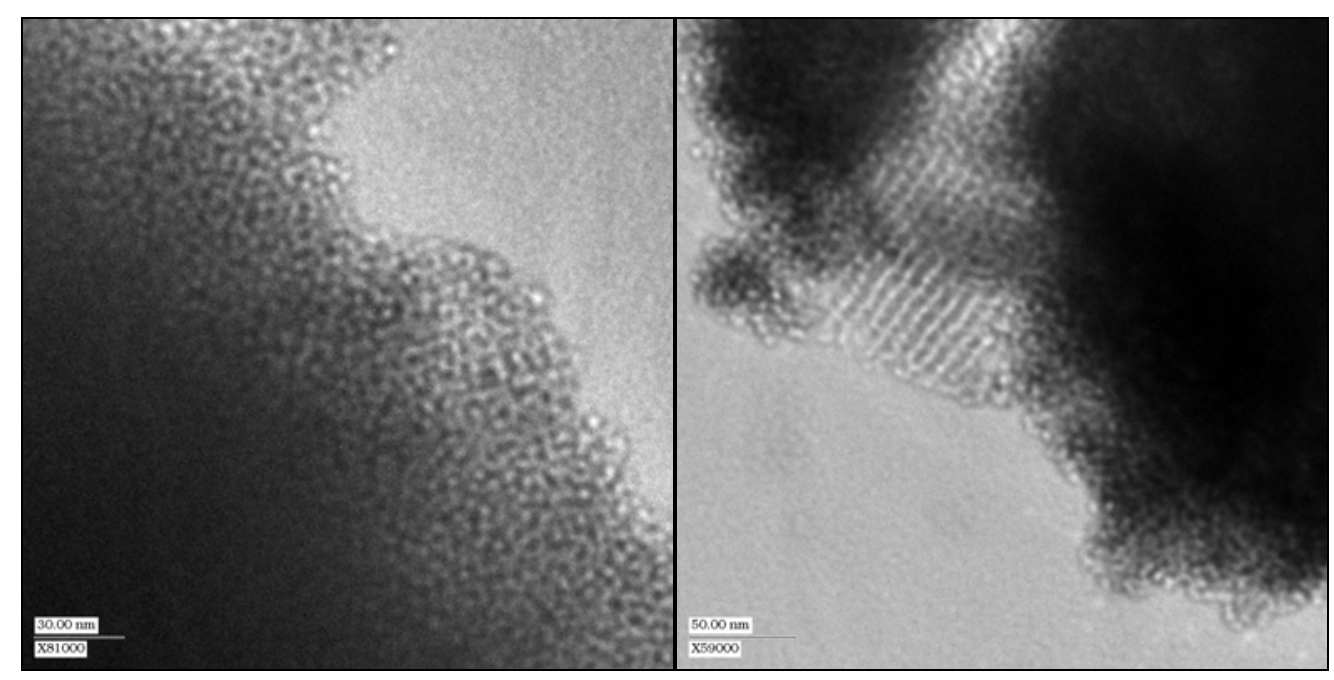

(a)

(b)

Figure 2. Transmission electron micrographs of mesoporous $\mathrm{SnO}_{2}$ (a) after calcination at $300{ }^{\circ} \mathrm{C}$ (incomplete removal of $\mathrm{CTABr}$ from the pores) and (b) after long-term tempering at $350{ }^{\circ} \mathrm{C}$ (complete removal).

Figure 4 shows the carbon monoxide (CO) gas-sensing performance of a representative mesoporous $\mathrm{SnO}_{2}$ material as well as of a commercially available $\mathrm{SnO}_{2}$-based sensor (GGS1330, supplied by UST) 
for comparison. A constant heating voltage of $4.2 \mathrm{~V}$ was applied during the measurements, corresponding to a temperature of about $300{ }^{\circ} \mathrm{C}$. The lower part of the Figure shows the $\mathrm{CO}$ concentration as well as the humidity of the test gas. The upper graphs show the relative change in conductance of the two sensors. Note that different scaling is used since the relative change in conductance is up to six times higher for the GGS1330 than for the mesoporous $\mathrm{SnO}_{2}$ sensors.

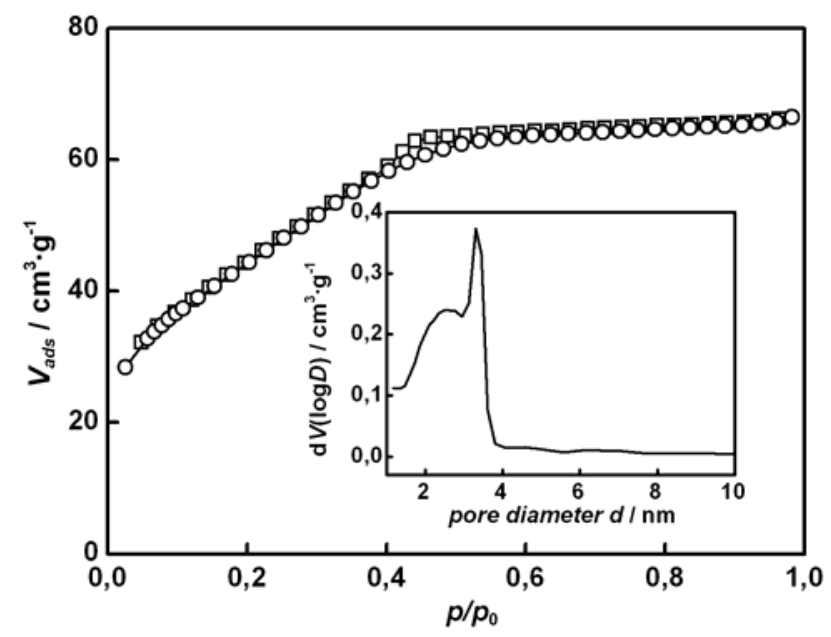

Figure 3. Nitrogen physisorption isotherms ( $\mathrm{O}$ adsorption, $\square$ desorption) of mesoporous $\mathrm{SnO}_{2}$. Inset: BJH pore size distribution.

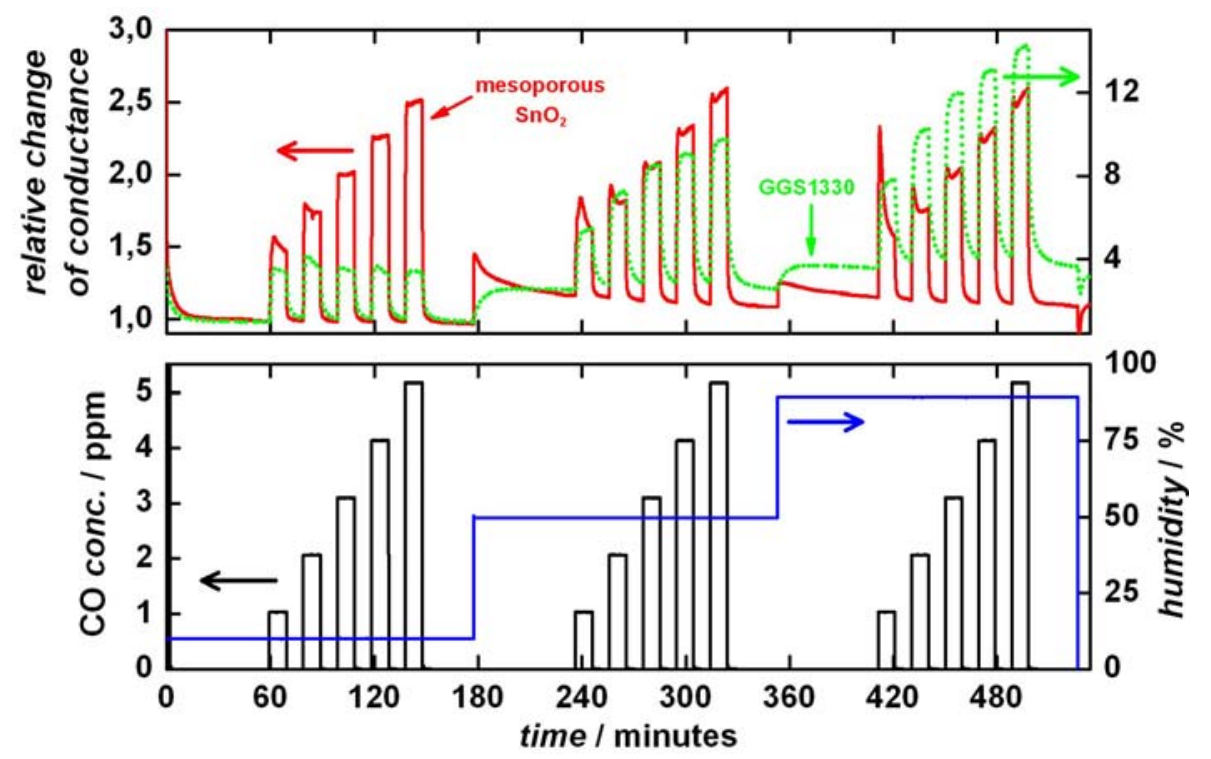

Figure 4. Gas sensor measurement showing the CO concentration (bottom, black line), the humidity (bottom, blue line), and the relative change of conductance of the sensor prepared with mesoporous $\mathrm{SnO}_{2}$ (top, red line) and of the commercial $\mathrm{SnO}_{2}$-based sensor (GGS1330, top, dotted green line).

The mesoporous $\mathrm{SnO}_{2}$ sensor shows a very stable base conductance and a quick response to CO. After switching on the CO flow the conductance signal changes from 10 to $90 \%$ of the maximum peak height within approximately 10 seconds. After increasing the humidity the base conductance decreases to its original level within 45 minutes. In comparison, the commercial GGS1330 sensor shows a similarly stable base conductance, but a considerably slower response to CO (85 seconds for the 10 to 
90\% rise). Furthermore, the reaction to the chance in humidity is significantly different, since the conductance does not return to its original base level. Thus, our mesoporous $\mathrm{SnO}_{2}$ sensors show a much higher signal stability against humidity of the test gas. This is shown more clearly in Figure 5 where the relative change in conductance is plotted against the CO concentration in dependence of the humidity.

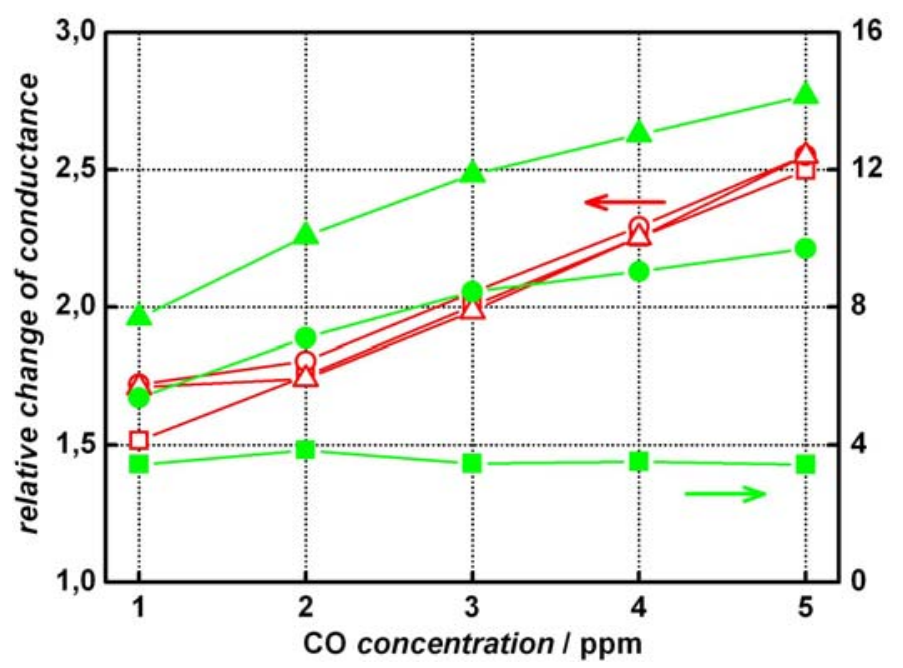

Figure 5. Relative change of conductance for various degrees of humidity: $\square 10 \%, \circ 50 \%, \Delta 90 \%$. Hollow red symbols: mesoporous $\mathrm{SnO}_{2}$; filled green symbols: commercial $\mathrm{SnO}_{2}$-based sensor (GGS1330).

\section{Conclusion}

In conclusion, we have shown that ordered mesoporous $\mathrm{SnO}_{2}$ powders with large specific surface area can be used for the preparation of gas sensors by application to commercial sensor supports. The materials show a fast and intense response to low concentrations of $\mathrm{CO}$ as well as a remarkably strong insensitivity against humidity. Additional measurements on the sensor response to other gases, including studies on the selectivity of our materials, will follow.

\section{References}

1. Kohl, D. Function and applications of gas sensors. J. Phys. D: Appl. Phys., 2001, 34, R125.

2. Madou, M.L.; Morrison, S.R. Chemical Sensing with Solid State Devices; Academic Press: London, 1989.

3. Beck, J.S.; Vartuli, J.C.; Roth, W.J.; Leonowicz, M.E.; Kresge, C.T.; Schmitt, K.D.; Chu, C. T.-W.; Olson, D.H.; Sheppard, E.W.; McCullen, S.B.; Higgins, J.B.; Schlenker, J.L. A new family of mesoporous molecular sieves prepared with liquid crystal templates. J. Am. Chem. Soc., 1992, 114, 10834.

4. Severin, K.G.; Abdel-Fattah, T.M.; Pinnavaia, T.J. Supramolecular assembly of mesostructured tin oxide. Chem. Commun., 1998,1471.

5. Chen, F.; Liu, M. Preparation of mesoporous tin oxide for electrochemical applications. Chem. Commun., 1999, 1829. 
6. (a) Wang, Y.; Ma, C.; Sun , X.; Li, H. Synthesis of mesoporous structured material based on tin oxide. Microporous Mesoporous Material, 2001, 49, 171.

(b) Wang, Y.-D.; Ma, C.-L.; Wu, X.-H.; Sun , X.-D.; Li, H.-D. Electrical and gas-sensing properties of mesostructured tin oxide-based $\mathrm{H}_{2}$ sensor. Sensors and Actuators B, 2002, 85, 270.

7. Srivastava, D.N.; Chappel, S.; Palchik, O.; Zaban, A.; Gedanken, A. Sonochemical synthesis of mesoporous tin oxide. Langmuir, 2002, 18, 4160.

8. (a) Hyodo, T.; Nishida, N.; Shimizu , Y.; Egishara, Y. Preparation and gas-sensing properties of thermally stable mesoporous $\mathrm{SnO}_{2}$. Sensors and Actuators B, 2002, 83, 209.

(b) Hyodo, T.; Abe, S.; Shimizu, Y.; Egashira, M. Gas-sensing properties of ordered mesoporous $\mathrm{SnO}_{2}$ and effects of coatings thereof. Sensors and Actuators B, 2003, 93, 590.

(C) 2006 by MDPI (http://www.mdpi.org). Reproduction is permitted for non-commercial purposes. 